\title{
Genetic diagnosis and treatment of a Chinese ketosis-prone MODY 3 family with depression
}

\author{
Jun Tang, Chen-Yi Tang, Fang Wang, Yue Guo, Hao-Neng Tang, Ci-La Zhou, Shu-Wen Tan, Shi-Ping Liu, \\ Zhi-Guang Zhou and Hou-De Zhou*
}

\begin{abstract}
Background: To analyze the gene mutation and mental disorder of a Chinese ketosis-prone diabetes (KPD) family, and to make a precise diagnosis and give a treatment for them.

Methods: We studied a Chinese family with a clinical diagnosis of maturity-onset diabetes of the young (MODY). The clinical data and the blood samples were collected. The promotor and coding regions inclusive intron exon boundaries of the HNF1A, HNF4A were detected by polymerase chain reaction (PCR) and direct sequencing. The missense mutation was also analyzed by bioinformatics. Genetic counseling was performed twice a month to relieve the mental disorder of the persons.

Results: The missense mutation c.779 C>T (p.T260M) in exon4 of HNF1A gene was detected, and the symptom heterogenicity among persons in this family were found. All the members were retreated with Gliclazide and stopped to use other medicine, the blood glucose of them were well controlled. We also performed an active genetic counseling to them and the mental disorder of the proband's sister was relieved.

Conclusions: A missense mutation of HNF1A gene was first found in Chinese ketosis-prone MODY family with manifestations heterogenicity among the persons. Sulphonylureas medicine and genetic counseling are efficiency ways to treat MODY 3 and its' mental disorder respectively.
\end{abstract}

Keywords: MODY, HNF1A, Mental health, Ketosis-prone diabetes

\section{Background}

Monogenic diabetes (MD) is genetically and clinically heterogeneous, which includes maturity-onset diabetes of the young (MODY), infancy-onset and neonatal diabetes mellitus and many rare forms of atypical diabetes, which accounts for approximately $1-2 \%$ of all diabetes, and is difficult to distinguish from type 1 and type 2 diabetes mellitus $[1,2]$. MODY is reported to be the most common form of MD and there are 14 MODY subtypes have been listed on the Online Mendelian Inheritance in Man (OMIM) database [3, 4]. Mutations in the GCK,

\footnotetext{
*Correspondence: houdezhou@csu.edu.cn

Department of Metabolism and Endocrinology, National Clinical Research Center for Metabolic Disease, The Second Xiang-Ya Hospital of Central South University, 139 Middle Ren-Min Road, Changsha, China
}

HNF1A, HNF4A, and HNF1B genes are the most common causes of MODY in the UK, and they represent different clinical characteristics respectively. The MODY2 persons got mild, subclinical hyperglycemia, which is generally present at birth and does not progress. MODY 1 and MODY 3 persons are tendency for microvascular complications and sensitivity to sulfonylureas [3]. MODY 3 is caused by hepatocyte nuclear factor-1A (HNF1A) gene mutation (also named as HNF1A-MODY), which accounts for $30-50 \%$ of MODY [3]. However, the mutations of HNF1A gene were detected in only 9\% Chinese people with MODY, and a majority of Chinese MODY people are due to the defection of unknown genes [5]. As absolute insulin deficiency is not typical for HNF1AMODY persons, the development of diabetic ketoacidosis (DKA) in a person with HNF1A-MODY is rare and 
just two previous cases are described [6,7], it is estimated that approximately $80 \%$ of MODY are misdiagnosed as type 1 or type 2 diabetes mellitus [8]. The limitations in physician's awareness and the restrictions in performing genetic testing are common reasons [9]. There are lots of studies focused on the relation between the young people with diabetes and mental health, no matter people with type 1 or type 2 diabetes mellitus, both of them are needed more psychological support [10]. Here, we reported a missense mutation of HNF1A gene was first found in Chinese ketosis-prone MODY family with manifestations heterogenicity among the persons. Sulphonylureas medicine and positive genetic counseling are efficiency to treat MODY 3 and its' mental disorder respectively.

\section{Methods}

\section{Clinical studies}

The study was approved by the Ethics Committee of the Second Xiang-Ya hospital of Central South University. Informed consent was obtained from all participants. Clinical information was obtained, which contain the current history, family history and so on.

\section{Genetic analysis}

Genomic DNA was extracted from blood samples with commercial kits (Qiagen). The previous descripted primers were used for exons, the intron-exon boundaries and the promoter regions of HNF1A and HNF4A were screened for mutations by polymerase chain reaction (PCR) amplification, and direct sequencing of the PCR products was performed as described previously [11].

\section{Islet autoantibody assay}

Serum antibodies to GAD, IA2, and ZnT8 were measured by radio binding assay with in vitro translated 35S-methionine-labelled GAD65, IA- 2, or ZnT8 [12].

\section{Islet autoantibody assay}

The participants were diagnosed as MODY3 and estimated the risk to develop the disorder to their relatives and/or to transmit it to offspring. Talking with the participants and their family twice a month in the first three months, and a systemic education was given to the patients to relieve the mental stress.

\section{Results}

The proband (III4 Fig. 1) was born in 1993 and diagnosed with diabetes in 2014. He was admitted to our hospital because of polydipsia, polyuria and weight loss for 6 months. His BMI was $19.96 \mathrm{~kg} / \mathrm{m}^{2}$, fasting blood glucose was $8.32 \mathrm{mmol} / \mathrm{L}, 2 \mathrm{~h}$-postprandial glucose was $20.02 \mathrm{mmol} / \mathrm{L}$, glycated hemoglobin (HbA1c) was

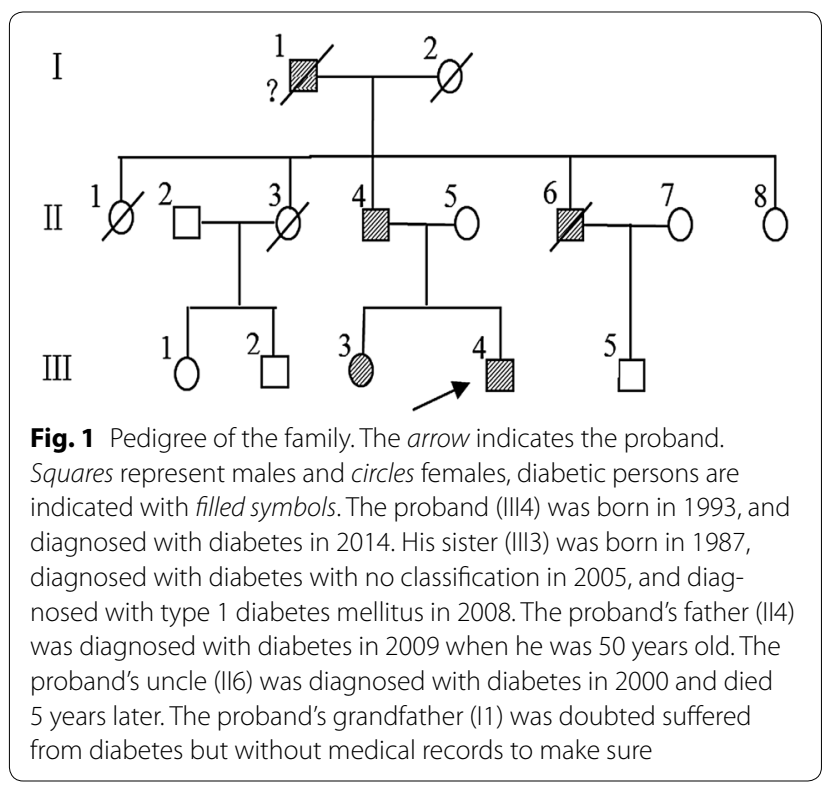

$54 \mathrm{mmol} / \mathrm{mol}$ (7.1\%), fasting c-peptide was $341.3 \mathrm{pmol} / \mathrm{L}$, and 2-h postprandial C-peptide was $926.4 \mathrm{pmol} / \mathrm{L}$. The islet autoantibodies glutamate decarboxylase (GAD), islet antigen-2 (IA-2) and zinc transporter 8 (ZnT8) were negative. The high-sensitivity $\mathrm{C}$-reactive protein (hs-CRP) was $0.09 \mathrm{mg} / \mathrm{L}$. Then, he was treated with gliclazide and metformin to control the blood glucose. The clinical features of the four participants are shown in Table 1.

The proband's sister (III3) was born in 1987 and diagnosed with diabetes in 2005. She was admitted to local hospital because of typical diabetic symptoms, and then was treated with glipizide, resulted in well blood glucose control and without hypoglycemic episodes, until to 2008. She was admitted to our hospital because of stopping taking glipizide for 3 months and with dizziness, vomiting and abdominal pain. Her fasting c-peptide was $201.65 \mathrm{pmol} / \mathrm{L}$, fasting blood glucose was $11.8 \mathrm{mmol} / \mathrm{L}$ and the urine ketones were $100 \mathrm{mg} / \mathrm{dL}$. The hs-CRP was $0.28 \mathrm{mg} / \mathrm{L}$. The diabetic ketosis was defined as urine ketones $\geq 80 \mathrm{mg} / \mathrm{dL}$ in the absence of acidosis [13]. Then she was diagnosed as ketosis-prone type 1 diabetes mellitus (KPD), the treatment was switched to the insulin aspart 30 and later a long-acting insulin analogue (glagine), and she got a well blood glucose control. The C-peptide level records of the person III3 are show in Table 2.

The proband's father (II4) was born in 1959 and diagnosed with diabetes in 2009, he had not any clinical symptom related to diabetes before 2009. He tested his blood glucose because of the mild polydipsia, polyuria for almost 1 year, and the blood glucose was mild increased. He took the metformin to control the blood 
Table 1 Clinical features of patients of the pedigree with maturity-onset diabetes of the young (HNF1A-MODY)

\begin{tabular}{|c|c|c|c|}
\hline & III3 & III4 & 114 \\
\hline Age (years) & 27 & 22 & 55 \\
\hline Age at diagnosis (years) & 18 & 21 & 49 \\
\hline BMI $\left(\mathrm{kg} / \mathrm{m}^{2}\right)$ & 16.45 & 19.96 & 18.90 \\
\hline $\mathrm{HbA} 1 \mathrm{C}$ mmol/mol (\%) & - & $54(7.1)$ & - \\
\hline $\mathrm{FBG}(\mathrm{mmol} / \mathrm{l})$ & 6.09 & 8.32 & 3.34 \\
\hline 2-h PPG (mmol/l) & 11.65 & 20.02 & - \\
\hline Fasting C-peptide (pmol/L) & 114.9 & 341.3 & - \\
\hline $\begin{array}{l}\text { 2-h postprandial C-peptide } \\
\text { (pmol/L) }\end{array}$ & - & 926.4 & 153.7 \\
\hline GAD-Ab & Negative & Negative & Negative \\
\hline $\mathrm{IA} 2-\mathrm{Ab}$ & Negative & Negative & Negative \\
\hline ZnT8-Ab & Negative & Negative & Negative \\
\hline Creatinine $(\mu \mathrm{mol} / \mathrm{L})$ & 59.9 & 69.0 & 66.3 \\
\hline Urea nitrogen (mmol/L) & 5.23 & - & 4.16 \\
\hline Uric acid $(\mu \mathrm{mol} / \mathrm{L})$ & 315.2 & 280.5 & 260.4 \\
\hline $\begin{array}{l}\text { Alanine aminotransferase } \\
(\mathrm{U} / \mathrm{L})\end{array}$ & 11.4 & 11.9 & 23.9 \\
\hline $\begin{array}{l}\text { Aspartate aminotransferase } \\
(\mathrm{U} / \mathrm{L})\end{array}$ & 23.1 & 15.8 & 33.4 \\
\hline Triglycerides (mmol/L) & 1.06 & 1.24 & 0.87 \\
\hline Total cholesterol (mmol/L) & 5.49 & 4.98 & 4.02 \\
\hline $\mathrm{HDL}-\mathrm{C}(\mathrm{mmol} / \mathrm{L})$ & 1.57 & - & 1.41 \\
\hline LDL-C (mmol/L) & 3.53 & - & 2.19 \\
\hline $\mathrm{Hs}-\mathrm{CRP}(\mathrm{mg} / \mathrm{L})$ & 0.09 & 0.28 & - \\
\hline Medication & Insulin & Sulphonylurea & Sulphonylurea \\
\hline
\end{tabular}

Table 2 The C-peptide level records of the patient III3

\begin{tabular}{lclc}
\hline Date & $\begin{array}{l}\text { Fasting C-pep- } \\
\text { tide }\end{array}$ & $\begin{array}{l}\text { 2-h postprandial } \\
\text { C-peptide }\end{array}$ & Reference value \\
\hline 2008.7 .31 & 201.65 & - & $223.40-$ \\
2009.4 .6 & 205.84 & 284.62 & $746.20 \mathrm{pmol} / \mathrm{l}$ \\
2009.9 .23 & 230.41 & 459.65 & \\
2012.2 .20 & 0.660 & 1.790 & $0.81-3.85 \mathrm{ng} / \mathrm{ml}$ \\
2012.11 .11 & 0.610 & 1.260 & \\
2013.7 .22 & 0.350 & 2.480 & \\
2015.9 .27 & 0.680 & 1.570 & \\
\hline
\end{tabular}

glucose. In 2013, he switched his treatment from metformin to glipizide by himself. From 2013 to 2014, he got sweating, palpitation, hunger for several times but no blood glucose data could be available when he got these symptoms. These symptoms indicated that he suffered from hypoglycemia.

According to the diagnosis age, insulin non-dependent at the onset and three consecutive generations were affected with obvious autosomal dominant inheritance. We considered the diagnosis was MODY. Because of the drug history and hypoglycemia symptoms of the proband's father, they were suspected to have HNF-1A or HNF-4A mutation. All people were given written informed consent before the genetic testing. As a result, the direct sequencing showed a heterozygous missense mutation c.779C $>$ T (p.T260M) in exon4 (Fig. 2), which was reported strongly associated with HNF1A-MODY. Two polymorphisms c.1375C $>$ T (p.L459L), c.1460G $>$ A (p.S487N) in exon7 of HNF-1A gene were detected, too.

According to the gene sequence, we estimated the secondary structure of T260M mutated HNF1A using software PSIPRED (Fig. 3). The position 260 is located near to a sheet structure. We thereafter performed protein 3D structure simulation using I-TASSER. Full-length amino acid sequence of HNF-1A (reference strain: NG_011731.2) was imported into I-TASSER and from the $\mathrm{COACH}$ result, the T260 is near nucleic acid binding site [14-17]. The STRUM result (Fig. 3) showed that the mutation destabilize the protein [18].

Then, their treatments were switched. The proband was treated with gliclazide MR $30 \mathrm{mg}$ per day, his sister switched insulin to glimepiride $2 \mathrm{mg}$ per day, and the dosage of gliclazide was decreased to his father. The proband got insomnia, anorexia, fatigue and lost interest for almost everything and then he was admitted to the psychiatric clinics. Because he worried about the diabetes would deteriorate soon and then he would die like his uncle in that young age; and he also worried about the inheritance of the diabetes, that he even could not found a family. The psychiatrist made a diagnosis of depression and anxiety state. He was treated with cymbalta and estazolam. After the gene diagnosis, the proband was obtained with the positive genetic counseling, which provided him the clinical health care, education, and especially emotional support to face this disease. Finally, the person was recovered and do not need antidepressant medication anymore.

\section{Discussion}

In this study, we reported a HNF1A-MODY family with a missense mutation in the exon 4 of HNF-1A gene c.779 C>T (p.T260M) which was first reported in 1997 [19], but it was the first time to be detected in Chinese population.

To date, although there were 414 different mutations of HNF1A-MODY have been reported worldwide [20], seldom of them were reported in China. Misdiagnosis were one of the reasons. The proband's sister was diagnosed with type 1 diabetes mellitus at age 21 . Her C-peptide could be detected (Table 2) and islet autoantibodies were negative, and her ketonuria were positive and without family history because the proband and his father had not diagnosed with diabetes at that time. In order to prevent the development of ketoacidosis, the insulin was taken to 


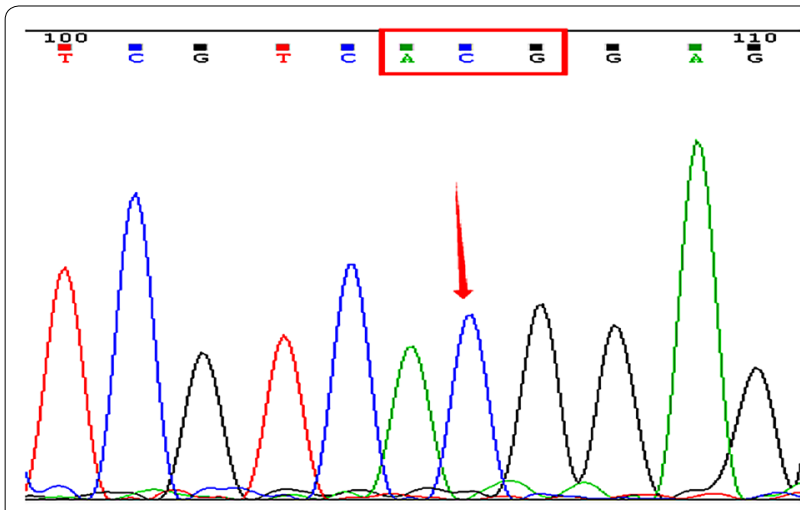

II 5
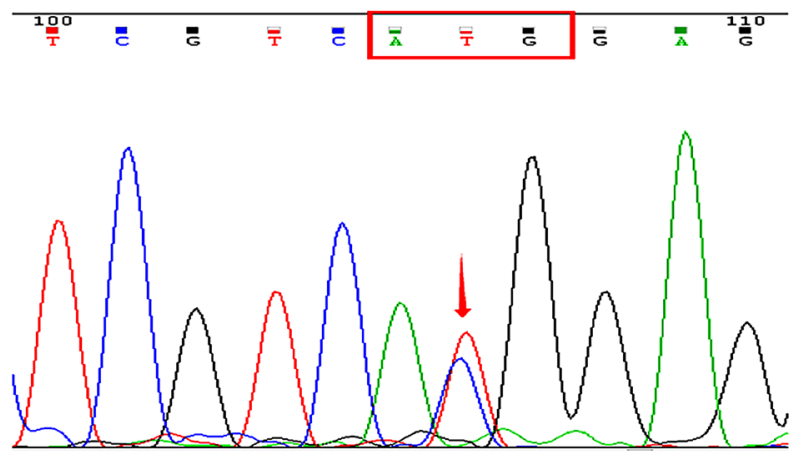

III 3

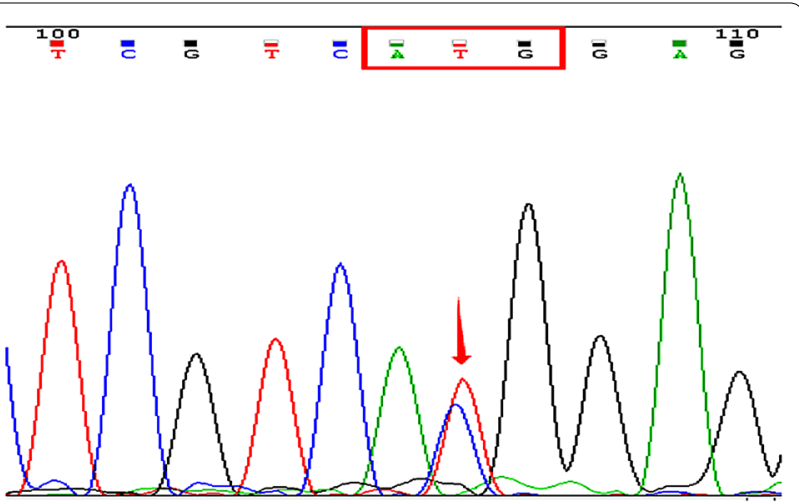

II 4

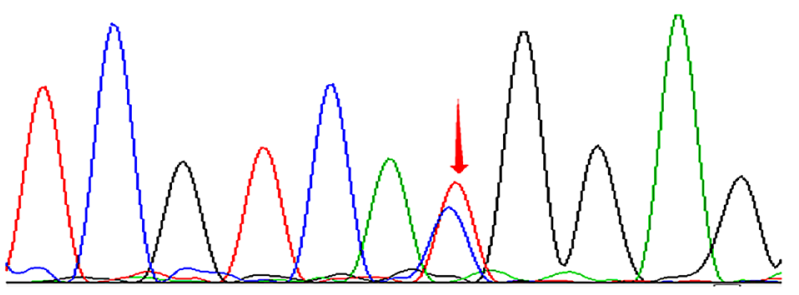

III 4 (The proband)

Fig. 2 Sequencing chromatograms of the family members (red arrow represents the mutation site). The genetic testing results of the family. A missense mutation C.779 C>T in exon 4 of HNF1A gene was detected in the proband (III4), his sister (III3), and his father (II4). No mutation was found in the same gene of his mother. This mutation was reported as a pathogenic gene of HNF1A-MODY

control the blood glucose and improve the metabolism. Even though there were two cases reported three people with HNF1A-MODY developed to severe DKA [6, 7], the present diagnostic recommendations suggest that the people with DKA would be excluded from MODY [21]. The proband's sister was not developed to DKA in this study probably because of the timely treatment, but the ketosis-prone clinical situation led to the misdiagnosis. According to the study of UK there were $5 \%$ of the people who were diagnosed with diabetes before the age of 45 suffering from MODY, but $80 \%$ of them misdiagnosed with type 1 or type 2 diabetes mellitus, which suggested that without considering the family history of diabetes or metabolic features, all people who were diagnosed up to the age of 30 with diabetes and C-peptide $\geq 0.2 \mathrm{nmol} / \mathrm{L}$ should be considered for HNF1A and HNF4A genes test [8]. If the proband's sister received the gene test at her first visiting, she will exempt from the insulin treatment.

The clinical phenotypes of the HNF1A-MODY people were heterogeneous even in a family with the same mutation, and both the environment and genetic factors may contributed to this phenomenon [22, 23]. Harries et al. discovered that the position of the mutation in the HFN1A gene was related to the age at the diagnosis of diabetes, and the age was lower if the missense mutations affecting the dimerization/DNA-binding domains than those affecting the transactivation domain. The 3D protein structure prediction has shown that the T260 was in the DNA-binding domains and the mutation T260M destabilize the protein, which indicates that the function of the protein has been affected and induced the diabetes. By Cotransfection experiments, Ekholm et al. showed that p.T260M mutation reduced the induction of the farnesoid X receptor (FXR) promoter and reduced the induction of the apical sodium-dependent bile salt transporter promoter [24], which indicated that p.T260M mutation leads to the functional changes of related gene. Three HNF1A isoforms were affected when the mutations were located in exon 1-6, and the diagnosis age of diabetes were younger than those with missense mutations involving one or two isoforms [25]. The missense mutation c.779 $\mathrm{C}>\mathrm{T}$ was in exon 4 of this family, and that 


\section{a secondary Structure Map}

Feature predictions are colour coded onto the sequence according to the sequence feature key shown below.

1 M V S K L S Q L Q T E L L A A L L E S G L S K E A L I Q A L G E E P G P Y L L L A G G E G P L D

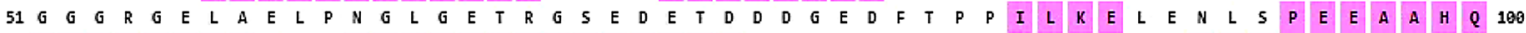
101 K A A V V V E E T L L L Q E E D 151 G T P M K K T

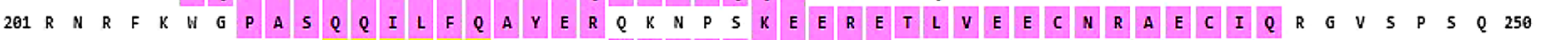
251 A $Q$ Q $G$ G L G G S N L L V 301 A H S S S P G L P P P A L S P $P$ S K V H G G V R Y G Q P A T S E T A E V V P S S S S S G G P 351 V S S P T G L E E P S 401 Q N N L I I M A S $S$ L $P$ P G V V M T T I G 4515 K 501 A L Y S S H K P E V V A Q Y T H T G L L P Q T K L L I T D T T T N L S A L A $S$ S L T T P T K K Q Q V F T $T$ S D $T$ T $E$ A $S$ S50

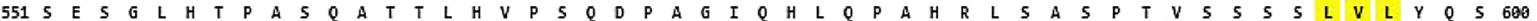
601 S D S S N G Q S H L L P S N H S V I E T F I S T Q M A S S S Q

$\begin{array}{llllll}\text { KEY Helix } & \text { Sheet } & \text { Disordered } & \begin{array}{l}\text { Disordered } \\ \text { protein binding }\end{array} & \begin{array}{l}\text { Dompred } \\ \text { Boundary }\end{array}\end{array}$

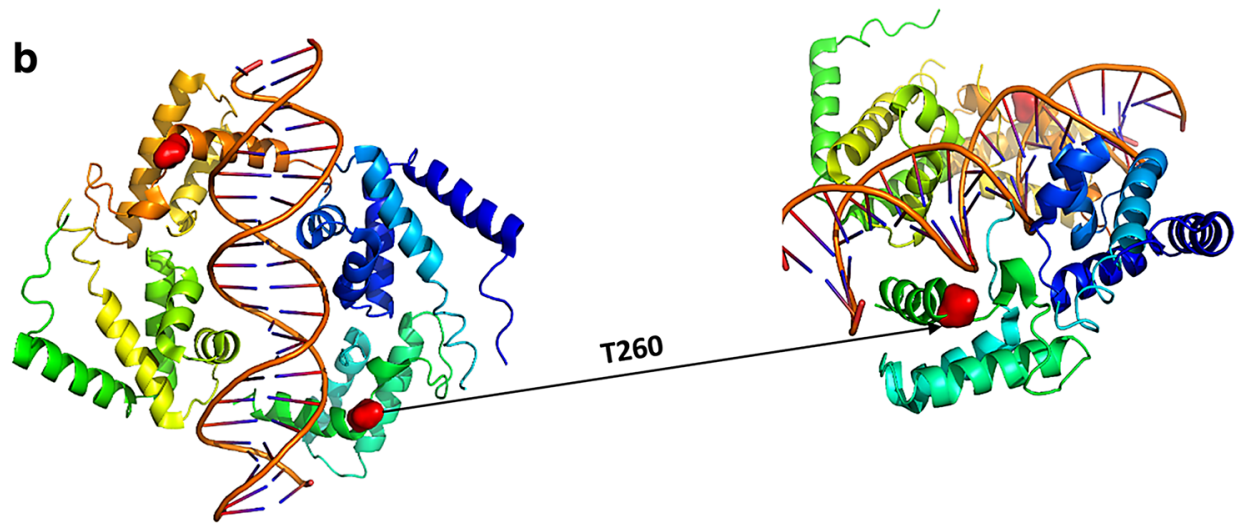

\section{c}

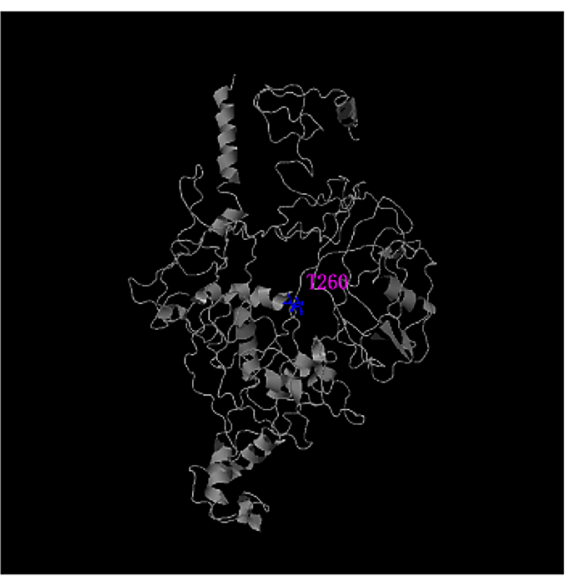

Fig. 3 The protein structure and function predictions. a Analysis of MODY 3 secondary structure. $\mathbf{b}$ Highlight of point mutation T260 at the 3D structure of MODY3. c The T260M mutation analysis, the STRUM results showed the T260M ddG is -0.15 
why the proband and his sister were diagnosed with diabetes at 21 and 18 years respectively. But their father got the diabetic symptoms and diagnosed at 50 years. The different lifestyles of two generations, and the proband's father, as a farmer, should always do farm work in his daily life, may play a role to delay the age at onset of diabetes effectively.

Sulfonylureas have been demonstrated could treated individuals with HNF1A-MODY effectively by acting on ATP-sensitive potassium channels [9]. Shepherd et al. discovered that the majority of people with MODY3 could transferred insulin to sulfonylureas successfully without deterioration in glycemic control [26]. The proband's older sister, who had taken the insulin to control blood glucose for almost 7 years, switched her treatment to glimepiride. The proband was treated with gliclazide only. The dosage of gliclazide was decreased for their father to avoid hypoglycemia episode. All the blood glucose of them was improved after changing the treatment (For the proband's sister the HbA1c decreased from 58 to $52 \mathrm{mmol} / \mathrm{mol}(7.5-6.9 \%)$. The treatment of proband's father played a key role in further gene test, which narrowed the gene screening scope. The medication history of clinical diagnosed MODY persons should be paid more attention to help doctors choose the appropriate gene test.

Mental disorder, such as depression and anxiety, in diabetes people have been aroused a lot of attention in recent years. Compared to the people without diabetes, the prevalence rate of depression is more than threetimes higher in people with type 1 diabetes mellitus and nearly twice as high in people with type 2 diabetes mellitus [27]. Browne et al. founded that the young adults with type 2 diabetes mellitus were more likely to have clinically meaningful depressive symptoms than the older adults [10]. They thought compared with the older type 2 diabetes mellitus people, the young adults with type 2 diabetes mellitus may need more intensive psychological and self-care support [10]. The mental disorder such as depressed mood may be lead to poor glycemic control [28]. The proband got metal disorder because several of his families got diabetes, and he thought the disease may be inherited to next generation. The possibility of insulin use may be another reason induced the mental disorder of the proband. After the diagnosis of MODY3 and the positive genetic counseling, the proband knew that this type of MODY is positively to sulphonylureas and he can have healthy children in future with the development of the genetic medicine. The timely genetic counseling is crucial to relief depression symptom of the proband and he doesn't need the anti-mental disorder medications.

The timely and positive genetic counseling is an effective way to help persons and their family to make informed, autonomous health care and reproductive decisions by providing the clinical health care, education, and emotional support [29,30], which will relief their mental pressure.

\section{Conclusions}

In summary, a missense mutation of HNF1A gene was first found in Chinese ketosis-prone MODY family with various clinical manifestations in different members. Sulphonylureas medicine and genetic counseling are efficiency ways to treat MODY 3 and its' mental disorder respectively.

\section{Abbreviations \\ MODY: maturity-onset diabetes of the young; HNF1A: hepatocyte nuclear fac- tor-1A; GAD-Ab: glutamate decarboxylase antibody; IA2-Ab: protein tyrosine phosphatase antibody; ZnT8-Ab: zinc transporter 8 antibody; HbA1c: glycated hemoglobin; hs-CRP: high-sensitivity C-reactive protein; BMI: body mass index; FBG: fasting blood glucose; PPG: postchallenge plasma glucose.}

\section{Authors' contributions}

HDZ designed and conducted of the study; JT, CYT, FW, SPL, ZGZ provided the data and performed the research; YG, HNT, CLZ and SWT analyzed and interpreted the data; and JT wrote the paper. All authors read and approved the final manuscript.

\section{Acknowledgements}

We thank all the participants who participated in this study.

\section{Competing interests}

The authors declare that they have no competing interests.

\section{Availability of data and materials}

All the necessary information has been provided along with the manuscript, however, the corresponding author can be contacted for any information related to this paper.

\section{Consent for publish}

The authors have authorization from all participants to publish the study findings.

\section{Ethics approval and consent to participate}

The study was approved by the Ethics Committee of the Second Xiang-Ya hospital of Central South University. Informed consent was obtained from all participants.

\section{Funding sources}

This work was supported by grants from the National Natural Scientific Foundation of China (Nos. 81370975, 81070278, 81401835), the Natural Science Foundation from Hunan Provincial (2015JC3012, 100JJ1007), and the Central South University (2010QZZD025).

Received: 14 October 2016 Accepted: 4 December 2016 Published online: 17 January 2017

References

1. Thomas ER, Brackenridge A, Kidd J, Kariyawasam D, Carroll P, Colclough K, Ellard S. Diagnosis of monogenic diabetes: 10-Year experience in a large multi-ethnic diabetes center. J Diabetes Investig. 2016;7:332-7.

2. Vaxillaire M, Froguel P. Monogenic Diabetes: Implementation of translational genomic research towards precision medicine. J Diabetes. 2016;8:782-95. 
3. Anik A, Catli G, Abaci A, Bober E. Maturity-onset diabetes of the young (MODY): an update. J Pediatr Endocrinol Metab. 2015;28:251-63.

4. Flannick J, Johansson S, Njolstad PR. Common and rare forms of diabetes mellitus: towards a continuum of diabetes subtypes. Nat Rev Endocrinol. 2016;12:394-406.

5. Xu JY, Dan QH, Chan V, Wat NM, Tam S, Tiu SC, Lee KF, Siu SC, Tsang MW, Fung LM, et al. Genetic and clinical characteristics of maturity-onset diabetes of the young in Chinese patients. Eur J Hum Genet. 2005;13:422-7.

6. Egan AM, Cunningham A, Jafar-Mohammadi B, Dunne FP. Diabetic ketoacidosis in the setting of HNF1A-maturity onset diabetes of the young. BMJ Case Rep. 2015. doi:10.1136/bcr-2014-209163.

7. Pruhova S, Dusatkova P, Neumann D, Hollay E, Cinek O, Lebl J, Sumnik Z. Two cases of diabetic ketoacidosis in HNF1A-MODY linked to severe dehydration: is it time to change the diagnostic criteria for MODY? Diabetes Care. 2013:36:2573-4.

8. Thanabalasingham G, Pal A, Selwood MP, Dudley C, Fisher K, Bingley PJ, Ellard S, Farmer AJ, McCarthy MI, Owen KR. Systematic assessment of etiology in adults with a clinical diagnosis of young-onset type 2 diabetes is a successful strategy for identifying maturity-onset diabetes of the young. Diabetes Care. 2012;35:1206-12.

9. Kavvoura FK, Owen KR. Maturity onset diabetes of the young: clinical characteristics, diagnosis and management. Pediatr Endocrinol Rev. 2012;10:234-42

10. Browne JL, Nefs G, Pouwer F, Speight J. Depression, anxiety and self-care behaviours of young adults with type 2 diabetes: results from the International Diabetes Management and Impact for Long-term Empowerment and Success (MILES) Study. Diabet Med. 2015;32:133-40.

11. Pruhova S, Ek J, Lebl J, Sumnik Z, Saudek F, Andel M, Pedersen O, Hansen T. Genetic epidemiology of MODY in the Czech republic: new mutations in the MODY genes HNF-4alpha, GCK and HNF-1 alpha. Diabetologia. 2003:46:291-5

12. Wang Z, Zheng Y, Tu Y, Dai Z, Lin J, Zhou Z. Immunological aspects of fulminant type 1 diabetes in Chinese. J Immunol Res. 2016:2016:1858202.

13. Zhang M, Li Y, Cui W, Yang P, Li H, Sheng C, Cheng X, Qu S. The clinical and metabolic characteristics of young-onset ketosis-prone type 2 diabetes in China. Endocr Pract. 2015;21:1364-71.

14. Yang J, Zhang Y. I-TASSER server: new development for protein structure and function predictions. Nucleic Acids Res. 2015;43:W174-81.

15. Yang J, Yan R, Roy A, Xu D, Poisson J, Zhang Y. The I-TASSER suite: protein structure and function prediction. Nat Methods. 2015;12:7-8.

16. Roy A, Kucukural A, Zhang Y. I-TASSER: a unified platform for automated protein structure and function prediction. Nat Protoc. 2010:5:725-38.

17. Zhang Y. I-TASSER server for protein $3 D$ structure prediction. BMC Bioinformatics. 2008:9:40.
18. Quan L, LV Q, Zhang Y. STRUM: structure-based prediction of protein stability changes upon single-point mutation. Bioinformatics. 2016;32:2936-46.

19. Glucksmann MA, Lehto M, Tayber O, Scotti S, Berkemeier L. Novel mutations and a mutational hotspot in the MODY3 Gene. Diabetes. 1996;46:1081-6.

20. Colclough K, Bellanne-Chantelot C, Saint-Martin C, Flanagan SE, Ellard S Mutations in the genes encoding the transcription factors hepatocyte nuclear factor 1 alpha and 4 alpha in maturity-onset diabetes of the young and hyperinsulinemic hypoglycemia. Hum Mutat. 2013;34:669-85.

21. Hattersley A, Bruining J, Shield J, Njolstad P, Donaghue KC. The diagnosis and management of monogenic diabetes in children and adolescents. Pediatr Diabetes. 2009;10(Suppl 12):33-42.

22. Fajans SS, Bell GI. MODY: history, genetics, pathophysiology, and clinical decision making. Diabetes Care. 2011;34:1878-84.

23. Bellanne-Chantelot C, Carette C, Riveline JP, Valero R, Gautier JF, Larger E, Reznik Y, Ducluzeau PH, Sola A, Hartemann-Heurtier A, et al. The type and the position of HNF1A mutation modulate age at diagnosis of diabetes in patients with maturity-onset diabetes of the young (MODY)-3. Diabetes. 2008:57:503-8.

24. Ekholm E, Nilsson R, Groop L, Pramfalk C. Alterations in bile acid synthesis in carriers of hepatocyte nuclear factor 1 a mutations. J Intern Med. 2013;274(3):263-72

25. Harries LW, Ellard S, Stride A, Morgan NG, Hattersley AT. Isomers of the TCF1 gene encoding hepatocyte nuclear factor-1 alpha show differential expression in the pancreas and define the relationship between mutation position and clinical phenotype in monogenic diabetes. Hum Mol Genet. 2006;15:2216-24.

26. Shepherd M, Shields B, Ellard S, Rubio-Cabezas O, Hattersley AT. A genetic diagnosis of HNF1A diabetes alters treatment and improves glycaemic control in the majority of insulin-treated patients. Diabet Med. 2009;26:437-41.

27. Roy T, Lloyd CE. Epidemiology of depression and diabetes: a systematic review. J Affect Disord. 2012;142:S8-21.

28. Lawrence JM, Standiford DA, Loots B, Klingensmith GJ, Williams DE, Ruggiero A, Liese AD, Bell RA, Waitzfelder BE, McKeown RE. Study SfDiY: prevalence and correlates of depressed mood among youth with diabetes: the SEARCH for Diabetes in Youth study. Pediatrics. 2006;117:1348-58

29. Choi J, Kim H. Effectiveness of the interventions utilized in genetic counseling. Adv Nurs. 2014;2014:1-19.

30. Ciarleglio LJ, Bennett RL, Williamson J, Mandell JB, Marks JH. Genetic counseling throughout the life cycle. J Clin Invest. 2003;112:1280-6.

\section{Submit your next manuscript to BioMed Central and we will help you at every step:}

- We accept pre-submission inquiries

- Our selector tool helps you to find the most relevant journal

- We provide round the clock customer support

- Convenient online submission

- Thorough peer review

- Inclusion in PubMed and all major indexing services

- Maximum visibility for your research

Submit your manuscript at www.biomedcentral.com/submit
BioMed Central 